\title{
Outcomes of Patients Who Undergo Transfusion of Fresh Frozen Plasma: A Prospective, Observational, Multicentre Cohort Study in Hiroshima, Japan
}

\author{
Aya Sugiyamal \\ Teruhisa Fujii ${ }^{2,3}$ \\ Yoshiko Okikawa ${ }^{4}$ \\ Fumie Sasaki ${ }^{5}$ \\ Masazumi Okajima ${ }^{3,6}$ \\ Hidekuni Hidaka ${ }^{3,7}$ \\ Koji Iwato 3,8 \\ Kazuyoshi Sato 3,9 \\ Akira Kokubunji $i^{3,10}$ \\ Noboru Takata ${ }^{3,1}$ । \\ Masahiro Yamamoto 3,12 \\ Junko Tanaka I,3
}

'Department of Epidemiology, Infectious Disease Control and Prevention, Graduate

School of Biomedical and Health Sciences, Hiroshima University, Hiroshima, Japan;

${ }^{2}$ Division of Transfusion Medicine, Hiroshima University Hospital, Hiroshima Japan; ${ }^{3}$ Joint Committee for Blood Transfusion Therapy in Hiroshima Prefecture, Hiroshima, Japan; ${ }^{4}$ Department of Oncology, Hiroshima City Hiroshima Citizens Hospital, Hiroshima, Japan;

${ }^{5}$ Division of Laboratory, Hiroshima City Hiroshima Citizens Hospital, Hiroshima, Japan; ${ }^{6}$ Department of Surgery, Hiroshima City Hiroshima Citizens Hospital, Hiroshima, Japan; ${ }^{7}$ Division of Surgical Services, Fukuyama City Hospital, Hiroshima, Japan; ${ }^{8}$ Department of Hematology, Hiroshima Red Cross Hospital \& Atomic-Bomb Survivors Hospital, Hiroshima, Japan; ' Division of Laboratory, Shobara Red Cross Hospital, Shobara, Japan; ${ }^{10}$ Department of Medical Science and Technology, Faculty of Health Sciences, Hiroshima International University, Hiroshima, Japan; "'Oda Internal Medical Clinic, Hiroshima, Japan; ${ }^{2}$ Hiroshima Red Cross Blood Centre, Hiroshima, Japan

Correspondence: Teruhisa Fujii Division of Transfusion Medicine, Hiroshima University Hospital, I-2-3, Kasumi, Minami-ward, Hiroshima, 734-855I, Japan Tel +8I-82-257-558।

Email terchan@hiroshima-u.ac.jp
Purpose: Given the chronic shortage of blood for transfusion in Japan, promotion of appropriate use of fresh frozen plasma (FFP) urgently needs to be addressed by the national blood project in Japan. Whether FFP transfusions are administered appropriately in Japan is currently unclear. In this study, we aimed to investigate the outcomes of patients who undergo FFP transfusion and the appropriateness of use of FFP.

Patients and Methods: This multicentre, prospective, observational cohort study was conducted from September 2017 to April 2019 at the 15 medical institutions in Hiroshima Prefecture that are the top providers of FFP. All patients who underwent FFP transfusion during the study period were included, relevant data being extracted from the medical records. The indications for FFP transfusion were classified in accordance with the Guidelines of the Ministry of Health, Labour and Welfare of Japan. Factors associated with patient outcomes at day 28 after FFP transfusion were subjected to multivariable logistic regression analysis.

Results: In total, data of 1299 patients were eligible for analysis. At least $63.8 \%$ of indications for FFP were in accordance with the guideline for FFP transfusions. The mortality rate at day 28 after FFP transfusion was $16.2 \%$. Older age (65-74 years: adjusted odds ratio $[\mathrm{AOR}]=4.3, \geq 75$ years: $\mathrm{AOR}=4.1)$, non-perioperative use $(\mathrm{AOR}=4.5)$, coagulopathy associated with liver damage $(\mathrm{AOR}=2.7)$, large volume of FFP transfused $(\mathrm{AOR}=2.5)$, and lack of improvement in blood coagulation following FFP transfusion were independently and significantly associated with death within 28 days after FFP transfusion.

Conclusion: Our findings do not support the simple conclusion that FFP transfusions contribute to prognosis. However, given that coagulopathy in patients with end-stage liver disease is infrequently improved by FFP transfusion, "inappropriate" use of FFP should be avoided. It is important to promote appropriate use of FFP so as not to waste blood resources.

Keywords: prognosis, coagulopathy, inappropriate use, compliance with guideline

\section{Introduction}

Though lower than in the USA and Germany, consumption of fresh frozen plasma (FFP) per 1000 people in Japan is still 1.4 times higher than in France and the UK. ${ }^{1}$ Within Japan, the difference in FFP consumption per bed is up to four times greater in the prefecture with the highest consumption than in that with the lowest consumption. Consumption in Hiroshima Prefecture has been relatively high. However, the number of blood donations in Japan is continually decreasing because the birth rate is declining and the population is ageing. ${ }^{2}$ Therefore, given the 
chronic shortage of blood for transfusion, promotion of appropriate use of FFP urgently needs to be addressed by the national blood project in Japan.

The Guideline for the Use of Blood Products formulated by the Ministry of Health, Labour and Welfare of Japan in 2005 states that a primary purpose of FFP transfusion is coagulant factor replacement in the absence of concentrated product. ${ }^{3}$ It also states that, to prevent overuse, neither prophylactic use of FFP nor its use in patients with terminal illness is indicated, despite the fact that FFP has historically often been transfused for these purposes. After the guideline had been updated in 2017 (Table 1), ${ }^{4}$ it came close to replicating international guidelines because it incorporated available evidence on blood transfusion. ${ }^{5-8}$ The former guideline provides values for prothrombin time, activated partial thromboplastin time (APTT), and fibrinogen concentration that should trigger FFP transfusion, ${ }^{3}$ whereas the revised guideline states that these values should not be used as triggers because they do not reliably predict a bleeding tendency. According to the Japanese guidelines, FFP transfusion is indicated to promote recovery from bleeding tendencies associated with coagulopathy or coagulation factor deficiency (eg, liver disease, disseminated intravascular coagulation, dilutional coagulopathy caused by massive red blood cell transfusion or fluid infusion), active bleeding alone not being a prerequisite for FFP transfusion. However, because many Japanese clinicians are not familiar with the revised guideline, some continue to transfuse FFP unnecessarily without determining the causes of the bleeding tendency.

Almost all of the many studies that have investigated the appropriate use of blood component products in Japan have reported only differences in, or annual changes in, the amounts used. ${ }^{8-10}$ Therefore, whether FFP is transfused in accordance with the guidelines or in eligible patients only remains unclear. Moreover, few studies have provided evidence for the efficacy of FFP transfusion. Although the massive transfusion of FFP mentioned in some guidelines was recently reported to be effective, ${ }^{11,12}$ the prognosis of patients who undergo FFP transfusion for other reasons is unknown. ${ }^{13-15}$

The Joint Committee for Blood Transfusion Therapy in Hiroshima Prefecture, which consists of representatives from the local government and major medical institutions, therefore conducted a multicentre, prospective, observational study on outcomes of patients who undergo FFP transfusion. Use of FFP in accordance with the Japanese guideline was also analysed as a secondary endpoint.

\section{Patients and Methods}

This multicentre, prospective, observational cohort study was conducted from September 2017 to April 2019 at the 15 medical institutions in Hiroshima Prefecture that are the top providers of FFP. All patients who received FFP transfusion in those institutions during the study period were included. They were registered at each institution, the goal being to enrol 1000 patients in total. In order to meet the purpose of this study and at the same time to minimize the on-site burden related to data collection, the following 11 items were extracted from the medical records: 1. age; 2. sex; 3. primary disease; 4. date and number of days of FFP transfusion; 5. whether FFP was used perioperatively (related to surgery) and, if so, the type of surgery performed; 6 . the indications for it, and dose of FFP; 7. coagulation test results before and after FFP use (prothrombin time-international normalised ratio [PT-INR], APTT, and fibrinogen concentration); 8. adverse reactions after FFP use; 9. presence and amount of red blood cell (RBC) transfusion; 10. duration of hospitalisation or discharge date; and 11. survival outcome 28 days after the first day of FFP transfusion. The indications for FFP transfusion were classified into the following categories in accordance with the Guidelines for the Use of Blood Products (revised in 2017 by the Ministry of Health, Labour and Welfare of Japan) (Table 1$):^{4}$ coagulopathy associated with liver disease, coagulopathy associated with disseminated intravascular coagulation (DIC), dilutional coagulopathy as a result of massive transfusion and fluid infusion, coagulation factor replacement in the absence of concentrated product, acute correction of warfarin effects, and plasma exchange. Although the indications for FFP were determined by the clinicians in each institution, they were reviewed during analysis because some were obviously wrongly classified. If FFP had been used in the absence of any of the indications in the guideline, its use was defined as "inappropriate". Massive transfusion was defined as transfusion of $\geq 10$ units of RBCs within 24 hours. Each recruiting institution sent their data to the central institution, Hiroshima University Hospital, after anonymisation. All data were compiled and analysed by the Department of Epidemiology, Infectious Disease Control and Prevention, Graduate School of Biomedical and Health Sciences, Hiroshima University. In the case of patients who had received multiple transfusions during the same episode, the data were merged and the FFP doses summed. When the same patient was 
Table I Guidelines for FFP Transfusion Established by Ministry of Health, Labour and Welfare of Japan (20I7)

\begin{tabular}{|c|c|c|c|}
\hline \multirow[t]{2}{*}{$\begin{array}{l}\text { Trigger values of coagulation tests (as } \\
\text { reference) }\end{array}$} & $\begin{array}{l}<\text { PT }> \\
<\text { APTT }>\end{array}$ & \multicolumn{2}{|c|}{$\begin{array}{l}\text { (i) INR } 2.0 \text { or higher, or (ii) } 30 \% \text { or lower } \\
\text { Above twice the upper limit of the standard value at each medical institution }\end{array}$} \\
\hline & $<$ Fibrinogen> & \multicolumn{2}{|c|}{$150 \mathrm{mg} / \mathrm{dL}$ or less, or when there is a risk of further deterioration } \\
\hline \multirow[t]{5}{*}{ Indications for FFP } & \multicolumn{3}{|c|}{ I) Coagulation factor supplementation } \\
\hline & & $\begin{array}{l}\text { a) Complex } \\
\text { coagulopathy }\end{array}$ & $\begin{array}{l}\text { i. Liver disease with bleeding tendency } \\
\text { ii. L-asparaginase administration related } \\
\text { ii. Disseminated intravascular coagulation (DIC) } \\
\text { iv. Dilutional coagulopathy caused by massive transfusion and } \\
\text { fluid infusion }\end{array}$ \\
\hline & & \multicolumn{2}{|c|}{$\begin{array}{l}\text { b) Coagulation factor replacement in the absence of concentrated product (when } \\
\text { bleeding or before invasive procedures) }\end{array}$} \\
\hline & & \multicolumn{2}{|c|}{ c) Correction of warfarin effect } \\
\hline & \multicolumn{3}{|c|}{ 2) Plasma exchange (thrombotic thrombocytopenic purpura, hemolytic-uremic syndrome) } \\
\hline \multirow[t]{5}{*}{ Inappropriate indications } & \multicolumn{3}{|c|}{ I. Expansion of circulatory volume } \\
\hline & \multicolumn{3}{|c|}{ 2. For nutritional purposes } \\
\hline & \multicolumn{3}{|c|}{ 3. For promotion of wound healing } \\
\hline & \multicolumn{3}{|c|}{ 4. Administration to terminal patients } \\
\hline & $\begin{array}{l}\text { 5. Prophylactic } \\
\checkmark \text { In case o } \\
\checkmark \text { Chronic } \\
\checkmark \text { Severe b } \\
\checkmark \text { Acute pa }\end{array}$ & $\begin{array}{l}\text { ransfusion } \\
\text { surgery or tra } \\
\text { er disease } \\
\text { ns } \\
\text { reatitis }\end{array}$ & does not require a large amount of blood transfusion \\
\hline
\end{tabular}

Abbreviations: FFP, fresh frozen plasma; PT, prothrombin time; INR, international normalised ratio; APTT, activated partial thromboplastin time.

enrolled more than once, each patient was included in the analysis if the purpose of FFP transfusion was different. If the purpose was the same but the reason for hospitalisation was different, we included each instance. During the study period, there were 1499 FFP transfusion events at the 15 recruiting medical institutions. After merging repeated use of FFP during the same episodes, 1299 patients were eligible for analysis.

\section{Statistical Analysis}

Coagulation test values of patients before and after FFP transfusion were compared using a paired $t$-test. Outcomes with and without massive transfusion of FFP $(\geq 2400 \mathrm{~mL})$ were compared by the $\chi^{2}$ test. After exclusion of cases of plasma exchange, factors associated with mortality 28 days after the first FFP transfusion were analysed using the $\chi^{2}$ test and logistic regression for univariate and multivariable analysis. In the multivariable analysis, sex, age, and amount of transfused FFP were forced entry predictors, the other 11 variables being selected using the stepwise method $(p<0.25)$. Statistical analysis was performed with JMP 14.2.0 (SAS Institute, Cary, NC, USA), and the significance level was set at 0.05 .

\section{Ethics}

There were no burdens or anticipated risks to patients as a result of the medical record review. In addition, decisions to transfuse FFP were made by the attending physician. The data were anonymised at each hospital before being sent to the central institution, and the created database was stored in a password-protected computer with no external connection. Careful consideration was given to the handling of personal information. An opt-out procedure was used for informed consent. The study was approved by the Ethics Committee of Hiroshima University (Approval No. E-976).

\section{Results}

The most common recipient age was within the seventh decade of life, accounting for $30.5 \%$ of the total sample (Figure 1) and $62.0 \%$ of the patients were men. The total 


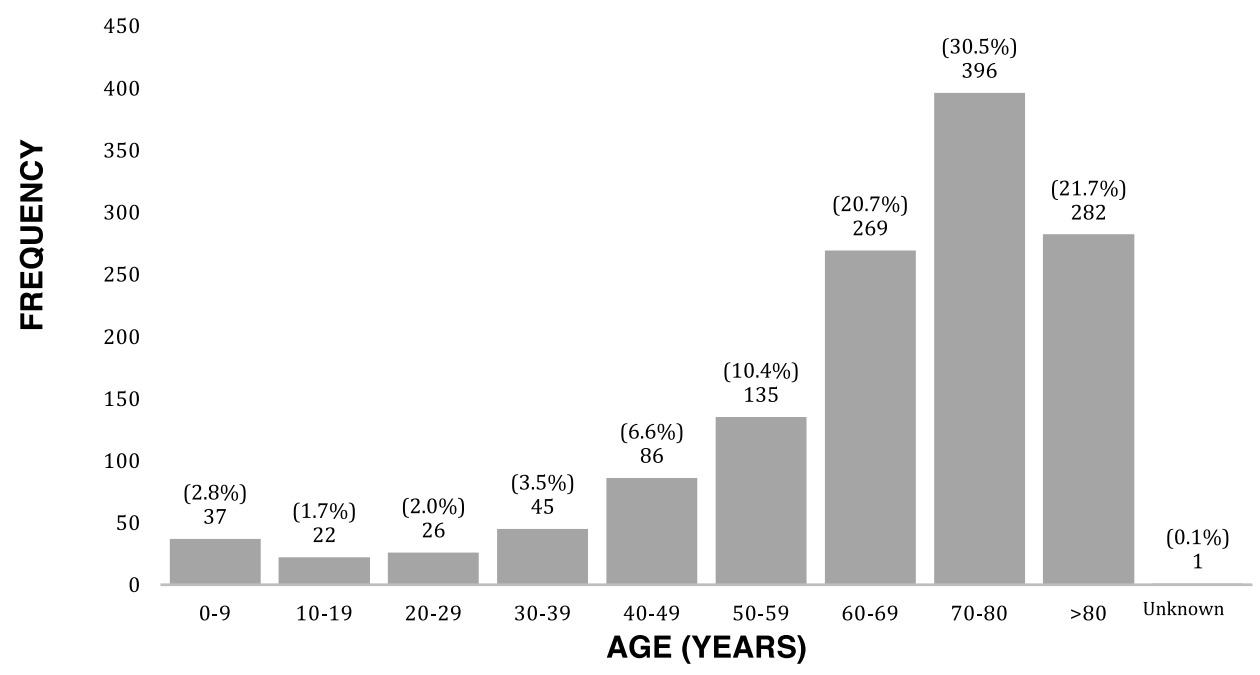

Figure I Age distribution of patients who underwent FFP transfusion

dose of FFP was 16,700 units (one unit is equivalent to $120 \mathrm{~mL}$ in Japan; thus, 16,700 units $=2,004,000 \mathrm{~mL}$ ). The median (min-max) FFP transfusion volume per patient was six (1-428) units. FFP was transfused perioperatively in $63.0 \%$ of cases, cardiovascular surgery being the most common form of surgery at $32.5 \%$.

The rates of performing coagulation tests before FFP transfusion were $90.3 \%$ for PT-INR, $85.4 \%$ for APTT, and $65.9 \%$ for fibrinogen. The post-transfusion test rates were 86.0\% for PT-INR, $79.2 \%$ for APTT, and $61.7 \%$ for fibrinogen. Trigger values stated in the former Japanese guideline were met for all three coagulation tests before FFP transfusion in $39.4 \%(512 / 1299)$ of cases, the values being confirmed to have improved after FFP transfusion in $18.2 \%(236 / 1299)$.

The indications for FFP transfusion are shown in Figure 2. "Inappropriate" was the most frequent, accounting for 473 cases (36.2\%), followed by dilutional coagulopathy (424 cases, $32.6 \%$ ), coagulopathy associated with DIC (155 cases, $11.9 \%$ ), and coagulopathy associated with liver disease (155 cases, 11.9\%). The main underlying diseases in the 473 patients who received FFP inappropriately were aortic dissection $(100 / 473,21.3 \%)$, ischaemic heart disease $(39 / 473,8.3 \%)$, and valvular disease (34/ $473,7.2 \%)$.

Outcomes 28 days after transfusion were $75.2 \%$ alive, $16.2 \%$ dead, and $8.5 \%$ unknown. There were no severe adverse effects related to FFP transfusion, such as transfusion-related acute lung injury or transfusion-associated circulatory overload. The results of coagulation tests before and after FFP transfusion by patient outcome 28 days after transfusion are shown in Table 2. There were significant improvements in all coagulation test values in the surviving patients ( $p<0.0001$ for all), but no significant improvement in the patients who had died (PT-INR, $\mathrm{p}=0.1954$; APTT, $\mathrm{p}=0.1891$; fibrinogen, $\mathrm{p}=0.6863$ ). The total number of days of FFP transfusion was also compared. Overall, FFP was transfused on significantly more days in the deceased group than in the surviving patients $(p<0.0001)$. Twenty or more units $(\geq 2400 \mathrm{~mL})$ of FFP were transfused in $15.2 \%$ (197/1299) of all patients. The main reasons for using such large amounts of FFP were dilutional coagulopathy (38.1\%), coagulopathy associated with DIC (17.8\%), and plasma exchange (17.3\%). The mortality rate was significantly higher among patients who underwent FFP transfusion of $\geq 20$ than $<20$ units (32.0\% vs $13.4 \%$, respectively; $p<0.0001, \chi^{2}$ test).

Excluding the 34 patients who received FFP for plasma exchange, factors associated with death 28 days after FFP transfusion were analysed using multivariable logistic regression. Older age (65-74 years: adjusted odds ratio [AOR], 3.5; 95\% confidence interval [95\% CI], 1.0-11.9; $\mathrm{p}=0.0463$ and $\geq 75$ years: AOR, 3.4; $95 \% \mathrm{CI}, 1.0-11.0$; $\mathrm{p}=0.0452$ ), non-perioperative use of FFP (AOR, 4.6; 95\% CI, 2.6-8.2; $\mathrm{p}<0.0001)$, coagulopathy associated with liver damage (AOR, 2.7; 95\% CI, 1.6-6.2; $\mathrm{p}=0.0190$ ), transfusion of seven or more units of FFP (AOR, 2.4; 95\% CI, 1.1-4.9; $\mathrm{p}=0.0175$ ), post-transfusion PT-INR of $\geq 2.0$ (AOR, 12.8; 95\% CI, 4.8-34.1; $\mathrm{p}<0.0001$ ), and posttransfusion APTT of $\geq 75$ seconds (AOR, 9.5; 95\% CI, $3.1-29.0 ; p<0.0001)$ were independently and significantly associated factors (Table 3). 


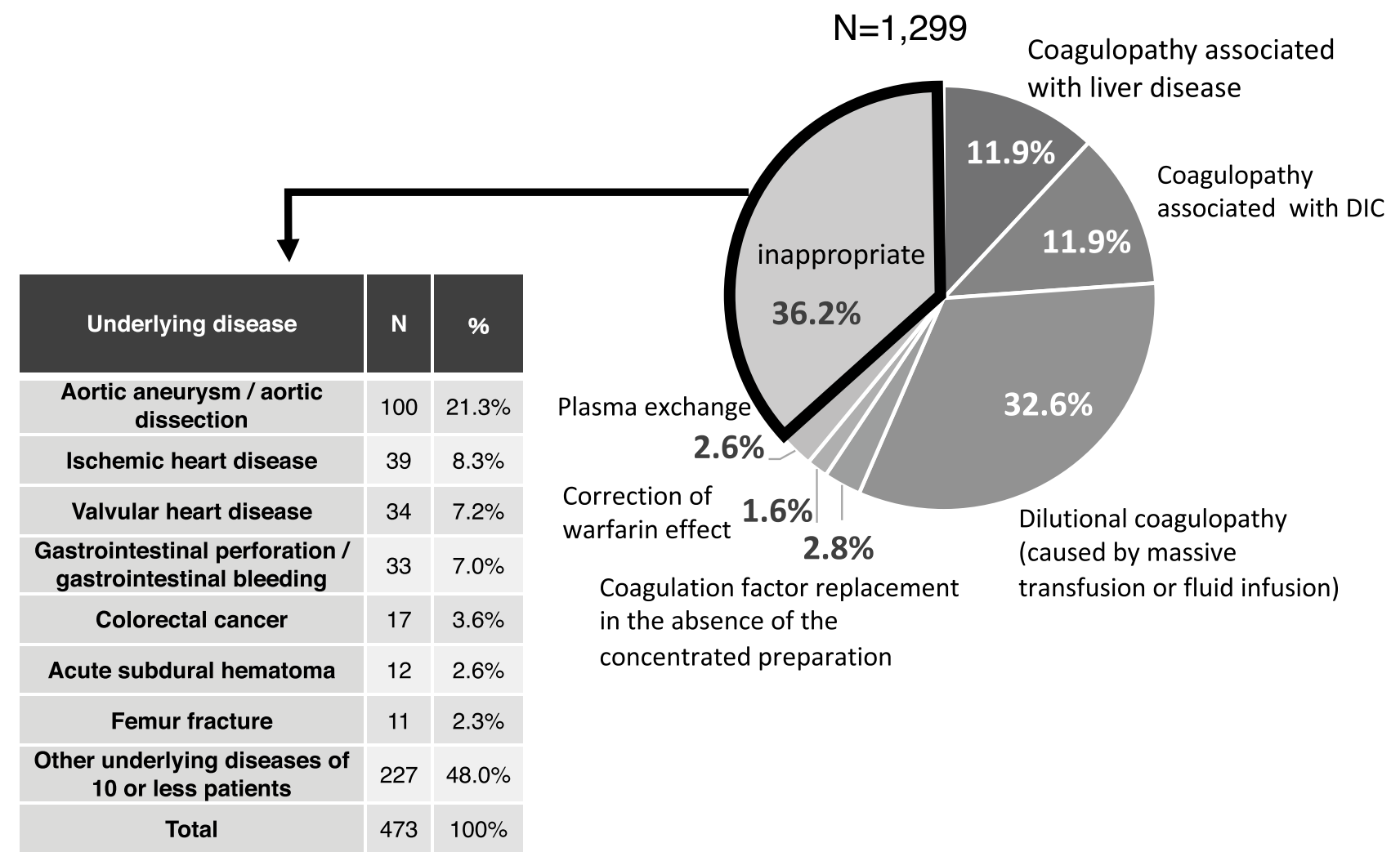

Figure 2 Distribution of indications for FFP transfusion, and underlying disease in which the reason for FFP use was "inappropriate".

\section{Discussion}

A major strength of this study is that all cases at 15 major medical institutions were registered prospectively for 1.5 years and that 1299 patients were analysed. In this study, the mortality rate 28 days after FFP transfusion was $16.2 \%$. We also found that a significant proportion of FFP use (36.2\%) was outside the indications in the Japanese guidelines (Table 1). The rate of inappropriate use of FFP has varied from $21 \%$ to $78 \%$ in surveys conducted in other regions. ${ }^{16-23}$ In comparison, the rate in this study was not very high. Conversely, $63.8 \%$ of transfused FFP was used appropriately according to the guideline. Considering the reported $70 \%$ compliance rate with the guideline in general medical practice, ${ }^{24,25}$ the use of FFP in Hiroshima appears to be largely in compliance with it. ${ }^{4}$

Table 2 Coagulation Test Values Before and After FFP Transfusion by Patients' Outcomes at Day 28

\begin{tabular}{|c|c|c|c|c|c|}
\hline & & $\mathbf{N}$ & Before FFP Transfusion & After FFP Transfusion & $\mathbf{P}^{*}$ \\
\hline \multirow[t]{3}{*}{ PT-INR } & Total & 1051 & $1.3(0.1-14.6)$ & I.2 (0.2-23.9) & $<0.0001$ \\
\hline & Alive & 826 & $1.3(0.1-14.1)$ & $1.2(0.2-23.9)$ & $<0.0001$ \\
\hline & Dead & $|5|$ & $1.6(0.9-14.6)$ & $1.5(0.9-5.6)$ & 0.1954 \\
\hline \multirow[t]{3}{*}{ APTT } & Total & 947 & $36.1(7.8-321)$ & $34.7(1.2-378)$ & $<0.0001$ \\
\hline & Alive & 746 & $34.9(7.8-200)$ & $33.5(1.2-378)$ & $<0.0001$ \\
\hline & Dead & 132 & $51.2(24.5-32 I)$ & $44.2(9.9-250)$ & 0.1891 \\
\hline \multirow[t]{3}{*}{ Fib } & Total & 654 & $206.6(I-965)$ & $236.9(1.2-1023)$ & $<0.0001$ \\
\hline & Alive & 541 & $213.7(1-965)$ & $246(I .2-90 I)$ & $<0.0001$ \\
\hline & Dead & 94 & $173.4(25-796)$ & $\mid 84.9(4 \mid-1023)$ & 0.6863 \\
\hline
\end{tabular}

Notes: Data are shown as median (min-max). *Paired $t$-test between before and after FFP transfusion.

Abbreviations: FFP, fresh frozen plasma; SD, standard deviation; PT-INR, prothrombin time-international normalised ratio; APTT, activated partial thromboplastin time; Fib, fibrinogen. 
Table 3 Univariate and Multivariate Analysis on Factors Associated with the Outcome at Day 28 After FFP Transfusion

\begin{tabular}{|c|c|c|c|c|c|c|}
\hline & \multicolumn{2}{|c|}{ Outcome at 28 Days } & \multicolumn{2}{|c|}{ Univariable Analysis* } & \multicolumn{2}{|c|}{ Multivariable Analysis\# } \\
\hline & Dead N (\%) & Alive N (\%) & OR $[95 \% \mathrm{CI}]$ & p-value & AOR $[95 \% \mathrm{Cl}]$ & p-value \\
\hline \multicolumn{7}{|l|}{ Age (years) } \\
\hline$\leq 39$ & $12(10.2)$ & 106(89.8) & 1 & & I & \\
\hline $40-64$ & $48(17.1)$ & $233(82.9)$ & $1.8[0.9-3.6]$ & 0.2337 & $1.7[0.5-5.7]$ & 0.4151 \\
\hline $65-74$ & $50(15.8)$ & $266(84.2)$ & $1.7[0.9-3.2]$ & 0.4029 & $3.5[1.0-11.9]$ & 0.0463 \\
\hline Over 75 & $89(20.3)$ & $349(79.7)$ & $2.3[1.2-4.3]$ & 0.0333 & $3.4[1.0-11.0]$ & 0.0452 \\
\hline \multicolumn{7}{|l|}{ Sex } \\
\hline Female & $66(15.2)$ & $368(84.8)$ & $0.8[0.6-1.1]$ & 0.1520 & $1.2[0.7-2.0]$ & 0.5223 \\
\hline Male & $133(\mid 8.5)$ & $586(81.5)$ & I & & I & \\
\hline \multicolumn{7}{|l|}{ Perioperative use of FFP } \\
\hline No & $128(31.9)$ & $273(68.1)$ & $4.8[3.4-6.6]$ & $<0.000$ I & $4.6[2.6-8.2]$ & $<0.0001$ \\
\hline Yes & $66(9.0)$ & $67 I(91.0)$ & I & & 1 & \\
\hline \multicolumn{7}{|l|}{ Indication for FFP } \\
\hline Coagulopathy caused by liver disease & $50(33.6)$ & $99(66.4)$ & $6.5[3.9-10.7]$ & $<0.000$ I & $2.7[1.2-6.2]$ & 0.0190 \\
\hline Coagulopathy associated with DIC & $48(33.1)$ & $97(66.9)$ & $6.4[3.8-10.5]$ & $<0.0001$ & $2.1[0.9-5.2]$ & 0.0922 \\
\hline Dilutional coagulopathy & $59(15.7)$ & $316(84.3)$ & $2.4[1.5-3.8]$ & $<0.0001$ & $1.4[0.6-2.9]$ & 0.4094 \\
\hline Coagulation factor replacement & $6(17.1)$ & 29(82.9) & $2.7[1.0-6.9]$ & 0.0368 & $1.3[0.2-7.2]$ & 0.7691 \\
\hline Warfarin effects correction & $6(30.0)$ & |4(70.0) & $5.5[2.0-15.4]$ & 0.0003 & $5.8[1.0-32.3]$ & 0.0613 \\
\hline Inappropriate use & $31(7.2)$ & $399(92.8)$ & I & & I & \\
\hline \multicolumn{7}{|l|}{ Pre-dose PT-INR } \\
\hline$\geq 2$ & $59(35.1)$ & $109(64.9)$ & $3.2[2.2-4.6]$ & $<0.000$ I & - & \\
\hline$<2$ & $130(14.6)$ & $76 I(85.4)$ & I & & & \\
\hline \multicolumn{7}{|l|}{ Pre-dose APTT(seconds) } \\
\hline$\geq 75$ & $49(48.0)$ & $53(52.0)$ & $5.6[3.7-8.7]$ & $<0.0001$ & $1.5[0.7-3.2]$ & 0.2760 \\
\hline$<75$ & $127(\mid 4.1)$ & $775(85.9)$ & 1 & & 1 & \\
\hline \multicolumn{7}{|l|}{ Pre-dose Fibrinogen (mg/dl) } \\
\hline$\leq 150$ & $61(26.8)$ & $167(72.3)$ & $2.2[1.5-3.2]$ & $<0.0001$ & & \\
\hline$>150$ & $78(14.3)$ & $468(85.7)$ & 1 & & & \\
\hline \multicolumn{7}{|l|}{ Amount of transfused FFP (Units) } \\
\hline$\geq 7$ & $127(22.8)$ & $43 \mid(77.2)$ & $2.1[1.5-2.9]$ & $<0.0001$ & $2.4[1.1-4.9]$ & 0.0175 \\
\hline$<7$ & $73(12.3)$ & $523(87.8)$ & 1 & & 1 & \\
\hline \multicolumn{7}{|l|}{$\begin{array}{l}\text { Amount of transfused RBC } \\
\text { (Units) }\end{array}$} \\
\hline$\geq 7$ & $92(20.7)$ & $352(79.3)$ & $1.5[1.1-2.1]$ & 0.0090 & $1.4[0.7-2.9]$ & 0.3116 \\
\hline$<7$ & $102(14.7)$ & $590(85.3)$ & I & & 1 & \\
\hline \multicolumn{7}{|l|}{ Ratio FFP/RBC } \\
\hline$>1.5$ & $59(23.5)$ & $192(76.5)$ & $1.8[1.2-2.6]$ & 0.0017 & $1.2[0.6-2.3]$ & 0.6373 \\
\hline$\leq 1.5$ & $99(14.8)$ & $572(85.3)$ & 1 & & 1 & \\
\hline \multicolumn{7}{|l|}{ Post-dose PT-INR } \\
\hline$\geq 2$ & $44(58.5)$ & $30(40.5)$ & II.7[7.0-19.4] & $<0.0001$ & $\mid 2.8[4.8-34.1]$ & $<0.0001$ \\
\hline$<2$ & $104(11.2)$ & $829(88.9)$ & 1 & & 1 & \\
\hline \multicolumn{7}{|l|}{ Post-dose APTT (seconds) } \\
\hline$\geq 75$ & $27(57.5)$ & $20(42.3)$ & $9.6[5.2-17.7]$ & $<0.0001$ & $9.5[3.1-29.0]$ & $<0.0001$ \\
\hline$<75$ & $109(12.3)$ & $776(87.7)$ & 1 & & 1 & \\
\hline
\end{tabular}

(Continued) 
Table 3 (Continued).

\begin{tabular}{|c|c|c|c|c|c|c|}
\hline & \multicolumn{2}{|c|}{ Outcome at 28 Days } & \multicolumn{2}{|c|}{ Univariable Analysis* } & \multicolumn{2}{|c|}{ Multivariable Analysis\# } \\
\hline & Dead N (\%) & Alive $\mathbf{N}(\%)$ & OR $[95 \% \mathrm{CI}]$ & p-value & AOR $[95 \% \mathrm{Cl}]$ & p-value \\
\hline \multicolumn{7}{|c|}{ Post-dose Fibrinogen $(\mathrm{mg} / \mathrm{dl})$} \\
\hline$\leq 150$ & $4 I(36.0)$ & $73(64.0)$ & $4.3[2.7-6.8]$ & $<0.0001$ & & \\
\hline$>150$ & $74(I 1.6)$ & $566(88.4)$ & 1 & & & \\
\hline \multicolumn{7}{|c|}{$\begin{array}{l}\text { Total number of days of FFP } \\
\text { administration (days) }\end{array}$} \\
\hline$\geq 3$ & $52(29.9)$ & $122(70.1)$ & $2.4[1.7-3.5]$ & $<0.0001$ & & \\
\hline$<2$ & $147(15.1)$ & $828(84.9)$ & 1 & & & \\
\hline
\end{tabular}

Notes: Excluding the cases of plasma exchange $(\mathrm{N}=34)$, factors associated with the mortality outcome at 28 days after FFP transfusion were analysed. *Chi-square test with post-hoc multiple comparisons by Bonferroni correction were used to compare groups. "Logistic regression analysis with the stepwise method: sex, age, and the amount of transfused FFP were forced entry predictors, and the other II variables were selected using the stepwise method $(p<0.25)$. $R^{2}=0.3084$, model $p$-value $<0.000 \mathrm{I}, \mathrm{n}=1265$. Abbreviations: OR, odds ratio; AOR, adjusted odds ratio; Cl, confidence interval; FFP, fresh frozen plasma; DIC, disseminated intravascular coagulation; APTT, activated partial thromboplastin time; PT-INR, prothrombin time and international normalized ratio; RBC, red blood cells.

Seventy-one (5.5\%) patients received FFP for $\geq 3$ days, and $28(2.2 \%)$ for $\geq 10$ days. Some of these patients may have had end-stage liver disease with coagulopathy because of impaired production of blood coagulation factors. Coagulopathy in patients with end-stage liver disease is difficult to eliminate, even with several FFP transfusions. This accounts for the tendency of clinicians to continue FFP transfusion over a long period, resulting in transfusion of large total volumes of FFP. In our study, patients who were still alive at 28 days had received FFP for significantly fewer days than those who had died. The mortality rate was also significantly higher in patients who had received $\geq 20$ units of FFP than in those who had received $<20$ units. We cannot simply conclude that a longer duration or a large amount of FFP transfusion leads to a poor prognosis. However, these findings do indicate that FFP is still given to patients with terminal conditions and poor prognoses, and that such use of FFP is inefficient.

The second edition of the Japanese guideline states that blood coagulation tests are not necessary before FFP transfusion; ${ }^{4}$ this differs from the recommendation in the first edition. However, in this study we found that, in most institutions, coagulation tests were performed to assess the patients' haemostatic status, assist decisions on whether to administer FFP, and determine the likely efficacy of FFP transfusion. Admittedly, the trigger values for the coagulation tests are only reference values. However, FFP may have been administered "inappropriately" to patients in whom one or more coagulation test results did not reach the trigger values. There were no significant differences in any coagulation test values between before and after FFP transfusion in the patients who subsequently died. This lack of improvement may indicate that patients whose conditions are very serious and who are at higher risk of dying have chronic rather than acute defects in coagulation.

The original purpose of FFP transfusion was not to improve patients' prognoses but to improve coagulation ability, stop bleeding, and reduce RBC transfusion volumes. However, because FFP should be administered only to eligible patients to prevent wasting of resources, determining survival rates after FFP transfusion is still important in Japan. Although $36.2 \%$ of FFP use was outside the indications and considered "inappropriate", this relatively low rate suggests that all "inappropriate" use of FFP was not fruitless. Some of these FFP transfusions may have improved coagulation ability and contributed to restoring good haemostasis, leading to a good prognosis. Even though the mortality rate in this study was $16.2 \%$, it cannot be concluded that FFP transfusion contributed to patients' prognoses.

We used multivariable logistic regression to analyse factors associated with death at day 28 after FFP transfusion. The factors independently and significantly associated with death at day 28 after FFP transfusion were older age, non-perioperative use of FFP, coagulopathy associated with liver damage, FFP transfusion of seven or more units, post-transfusion PT-INR of $\geq 2$, and posttransfusion APTT of $\geq 75$ seconds. Patients with end-stage liver disease often have chronic coagulopathy that does not improve with FFP transfusion. 
This study had several limitations. First, although bleeding volume is a mortality-related factor, it could not be included in the multivariable analysis. In addition, we did not include the patients' underlying diseases in the multivariable analysis because they were too diverse. As to specific causes of death, we confirmed that no deaths were due to bleeding. However, we did not further investigate the causes of death.

This is the first study to comprehensively determine the actual circumstances and outcomes of FFP transfusion in major medical institutions in Hiroshima Prefecture. Surveys need to be performed in other prefectures and nationwide and the results compared with those of this study. Our findings indicate that it is necessary to continue to promote appropriate FFP use to minimise wasting of blood resources.

\section{Conclusion}

In this multicentre prospective cohort study, which was performed to determine the actual circumstances and outcomes of FFP transfusion in Hiroshima Prefecture, we found that FFP was transfused appropriately in at least $63.8 \%$ of cases. The mortality rate 28 days after transfusion was $16.2 \%$. The factors independently and significantly associated with mortality were older age, non-perioperative use of FFP, coagulopathy associated with liver damage, FFP transfusion of seven or more units, post-transfusion PT-INR of $\geq 2$, and posttransfusion APTT of $\geq 75$ seconds.

\section{Acknowledgments}

We thank the following institutions in Hiroshima for their contributions to this survey: Hiroshima University Hospital, Hiroshima City Asa Citizens Hospital, Hiroshima Prefectural Hospital, Kure Kyosai Hospital, JA Onomichi General Hospital, JA Hiroshima General Hospital, Hiroshima City Hiroshima Citizens Hospital, Hiroshima-Nishi Medical Center, Hiroshima Red Cross Hospital \& Atomic-bomb Survivors Hospital, Miyoshi Central Hospital, Shobara Red Cross Hospital, Higashi Hiroshima Medical Center, Onomichi Municipal Hospital, National Hospital Organization Fukuyama Medical Center, and Fukuyama City Hospital.

We also thank Dr Trish Reynolds, MBBS, FRACP, from Edanz (https://jp.edanz.com/ac) for editing a draft of this manuscript.

\section{Author Contributions}

All authors made a significant contribution to the work reported, whether that was in the conception, study design, execution, acquisition of data, analysis and interpretation, or in all these areas. Especially, Aya Sugiyama and Junko Tanaka had a great contribution to analysing the data. Aya Sugiyama and Teruhisa Fujii mainly wrote the manuscripts, and the rest of all authors critically reviewed it. All authors gave final approval of the manuscript version to be published and agreed to be accountable for every aspect of the work.

\section{Funding}

This work was supported by a Political Research Grant for Appropriate Use of Blood Product in 2017 and 2018 from the Ministry of Health, Labour and Welfare of Japan.

\section{Disclosure}

Dr Masazumi Okajima reports grants from Ministry of Health, Labour and Welfare of Japan, during the conduct of the study; personal fees from Chugai Pharmaceutical Co., Ltd., Taiho Pharma, Johnson and Johnson K. K., Medicaroid Corporation, Eli Lily Japan K. K., Olympus Corporation, and Covidien Japan Inc., outside the submitted work. The authors declare that they have no other conflicts of interest in this work.

\section{References}

1. Ministry of Health. Labour and welfare of Japan: annual report on national blood project in 2016. Available from: https://www.mhlw.go.jp/stf/seisaku nitsuite/bunya/0000154567.html. Accessed December 9, 2020.

2. Ministry of Health. Labour and welfare of Japan: annual report on national blood project in 2020. Available from: https://www.mhlw.go.jp/stf/seisaku nitsuite/bunya/0000063233.html. Accessed August 4, 2021.

3. Ministry of Health. Labour and welfare of Japan: the guideline for the use of blood products. First edition. Available from: https://www. mhlw.go.jp/new-info/kobetu/iyaku/kenketsugo/5tekisei3b.html.

Accessed December 7, 2020.

4. Ministry of Health. Labour and welfare of Japan: the guideline for the use of blood products (revised in 2017). Available from: https://www. mhlw.go.jp/file/06-Seisakujouhou-11120000-Iyakushokuhinkyoku 10000161115.pdf. Accessed December 9, 2020.

5. Liumbruno G, Bennardello F, Lattanzio A, et al. Recommendations for the transfusion of plasma and platelets. Blood Transfus. 2009;7:132-150.

6. O’Shaughnessy DF, Atterbury C, Bolton Maggs P, et al. Guidelines for the use of fresh-frozen plasma, cryoprecipitate and cryosupernatant. $\mathrm{Br}$ J Haematol. 2004;126:11-28. doi:10.1111/j.1365-2141.2004.04972.x

7. Roback JD, Caldwell S, Carson J, et al. Evidence-based practice guidelines for plasma transfusion. Transfusion. 2010;50:1227-1239. doi:10.1111/j.1537-2995.2010.02632.x

8. Makino S, Konno H, Okamoto Y, et al. Current status and future issues in blood transfusion therapy in Japan: a nationwide survey. Jpn J Transfus Cell Ther. 2020;66:619-628. doi:10.3925/jjtc.66.619

9. Makino S, Tanaka A, Takahashi K, et al. Nationwide questionnaire survey of transfusion medicine in fiscal year 2008- Analysis of transfusion management systems and the appropriateness of transfusion therapy. Jpn J Transfus Cell Ther. 2010;56:515-521. doi:10.3925/ jjtc. 56.515 
10. Kanno H, Okamoto H, Kitazawa J, et al. Nationwide questionnaire survey of transfusion medicine in fiscal year 2017. Jpn J Transfus Cell Ther. 2018;64:752-760. doi:10.3925/jjtc.64.752

11. Borgman MA, Spinella PC, Holcomb JB, et al. The effect of FFP: $\mathrm{RBC}$ ratio on morbidity and mortality in trauma patients based on transfusion prediction score. Vox Sang. 2011;101:44-54. doi:10.1111/ j.1423-0410.2011.01466.x

12. Zehtabchi S, Nishijima DK. Impact of transfusion of fresh-frozen plasma and packed red blood cells in a 1:1 ratio on survival of emergency department patients with severe trauma. Acad Emerg Med. 2009;16:371-378. doi:10.1111/j.1553-2712.2009.00386.x

13. Zhang LM, Li R, Zhao XC, et al. Increased transfusion of fresh frozen plasma is associated with mortality or worse functional outcomes after severe traumatic brain injury: a retrospective study. World Neurosurg. 2017;104:381-389. doi:10.1016/j.wneu.2017.0 4.140

14. Shiba H, Ishida Y, Haruki K, et al. Negative impact of fresh-frozen plasma transfusion on prognosis after hepatic resection for liver metastases from colorectal cancer. Anticancer Res. 2013;33:27 23-2728.

15. Müller MC, Arbous MS, Spoelstra-de Man AM, et al. Transfusion of fresh-frozen plasma in critically ill patients with a coagulopathy before invasive procedures: a randomized clinical trial. Transfusion. 2015;55:26-35. doi:10.1111/trf.12750

16. Kakkar N, Kaur R, Dhanoa J. Improvement in fresh frozen plasma transfusion practice: results of an outcome audit. Transfus Med. 2004;14:231-235. doi:10.1111/j.0958-7578.2004.00505.x

17. Luk C, Eckert KM, Barr RM, et al. Prospective audit of the use of fresh-frozen plasma, based on Canadian Medical Association transfusion guidelines. CMAJ. 2002;166:1539-1540.
18. Stanworth SJ, Grant-Casey J, Lowe D, et al. The use of fresh-frozen plasma in England: high levels of inappropriate use in adults and children. Transfusion. 2011;51:62-70. doi:10.1111/j.1537-2995.20 10.02798.x

19. Tinmouth A, Thompson T, Arnold DM, et al. Utilization of frozen plasma in Ontario: a provincewide audit reveals a high rate of inappropriate transfusions. Transfusion. 2013;53:2222-2229.

20. Moiz B, Arif FM, Hashmi KZ. Appropriate and inappropriate use of fresh frozen plasma. J Pak Med Assoc. 2006;56:356-359.

21. Qiang JK, Thompson T, Callum J, et al. Variations in RBC and frozen plasma utilization rates across 62 Ontario community hospitals. Transfusion. 2019;59(2):545-554. doi:10.1111/trf.15070

22. Shinagare SA, Angarkar NN, Desai SR, et al. An audit of fresh frozen plasma usage and effect of fresh frozen plasma on the pre-transfusion international normalized ratio. Asian J Transfus Sci. 2010;4(2):128-132. doi:10.4103/0973-6247.67024

23. Goel R, Patel EU, White JL, et al. Factors associated with red blood cell, platelet, and plasma transfusions among inpatient hospitalizations: a nationally representative study in the United States. Transfusion. 2019;59(2):500-507. doi:10.1111/trf.15088

24. Arts DL, Voncken AG, Medlock S, Abu-Hanna A, van Weert HC. Reasons for intentional guideline non-adherence: a systematic review. Int $J$ Med Inform. 2016;89:55-62. doi:10.1016/j.ijmedinf.201 6.02 .009

25. Cordasco KM, Yuan AH, Danz MJ, et al. Veterans health administration primary care provider adherence to prescribing guidelines for systemic hormone therapy in menopausal women. J Healthc Qual. 2019;41:99-109. doi:10.1097/JHQ.0000000000000183
Journal of Blood Medicine

\section{Publish your work in this journal}

The Journal of Blood Medicine is an international, peer-reviewed, open access, online journal publishing laboratory, experimental and clinical aspects of all aspect pertaining to blood based medicine including but not limited to: Transfusion Medicine; Blood collection, Donor issues, Transmittable diseases, and Blood banking logistics; Immunohematology; Artificial and alternative blood based therapeutics; Hematology; Biotechnology/nanotechnology of blood related medicine; Legal aspects of blood medicine; Historical perspectives. The manuscript management system is completely online and includes a very quick and fair peer-review system. Visit http://www.dovepress.com/testimonials.php to read real quotes from published authors. 